\title{
Recomendações para alimentação complementar de crianças menores de dois anos'
}

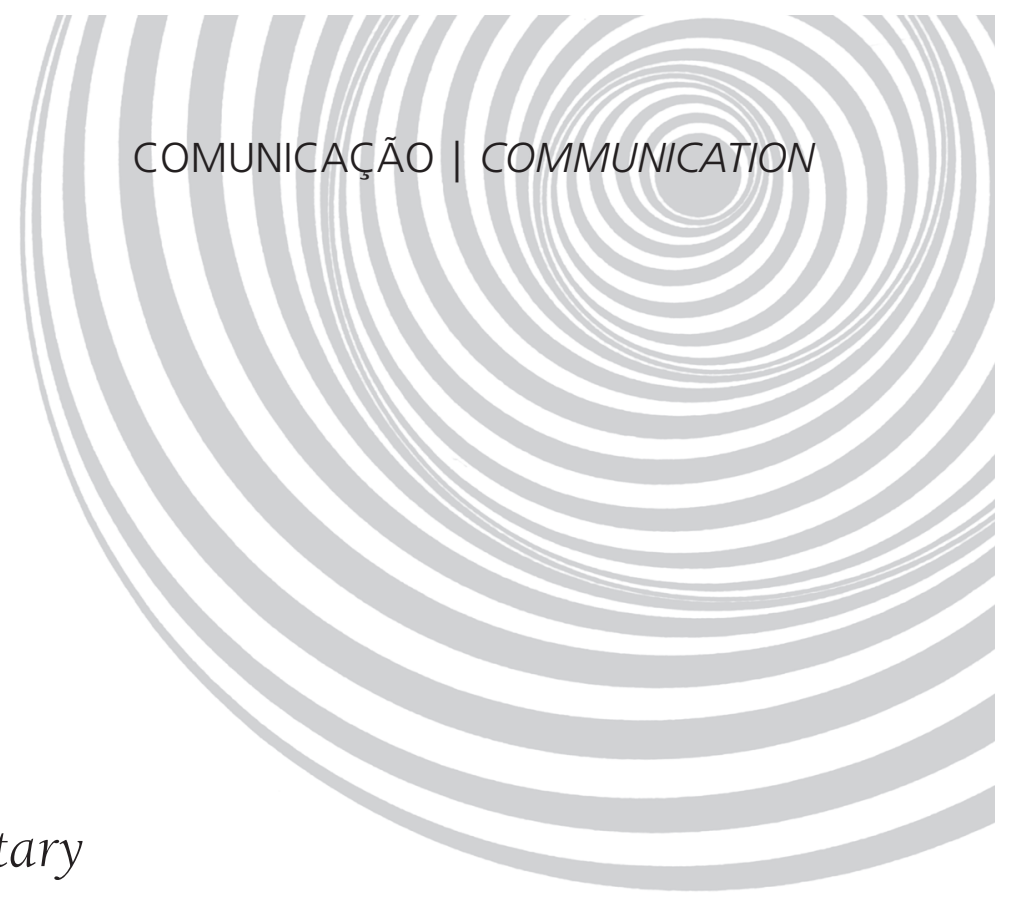

\author{
Recommendations for the complementary \\ feeding of children under \\ age two years
}

Mara Cláudia Azevedo Pinto DIAS²

Lincoln Marcelo Silveira FREIRE ${ }^{3}$ (In memoriam)

Sylvia do Carmo Castro FRANCESCHINI ${ }^{4}$

RESU M O

O presente estudo teve por objetivo revisar as recomendações atuais sobre a alimentação complementar de crianças menores de dois anos a partir da pesquisa em banco de dados - SciELO, MedLine e Lilacs - e de publicações da Organização Mundial da Saúde e do Ministério da Saúde. Utilizou-se o descritor desmame ou weaning e definiram-se os limites de crianças de 0 a 23 meses, período de publicação de 2002 a 2006 e idioma de redação em português, inglês e espanhol. Nos últimos anos acumularam-se evidências científicas sobre a importância da amamentação exclusiva nos primeiros seis meses, da alimentação complementar oportuna e da manutenção do aleitamento materno até os dois anos ou mais. A alimentação complementar adequada deve compreender alimentos ricos em energia, proteína e micronutrientes, sem contaminação, sem excesso de sal ou condimentos, em quantidade apropriada, fáceis de preparar, assegurando-se a consistência e a densidade energética adequadas. A família tem papel decisivo na formação de novos hábitos, no autocontrole da ingestão alimentar e na formação de um padrão de comportamento alimentar que pode ser adequado ou não. A introdução da alimentação complementar é uma etapa crítica e vários são os prejuízos do aleitamento artificial e da introdução precoce e/ou inadequada dos alimentos. Aos profissionais da saúde cabe orientar os pais quanto às práticas da alimentação complementar apropriada e orientar as ações governamentais, tendo como objetivo máximo o crescimento e o desenvolvimento pleno das crianças menores de dois anos.

Termos de indexação: Aleitamento materno. Alimentação complementar. Desmame. Lactente.

\footnotetext{
$\overline{1}$ Artigo elaborado a partir dissertação de M.C.A.P. DIAS, intitulada "Perfil da alimentação complementar de lactentes atendidos em uma clínica particular de Belo Horizonte, Minas Gerais". Instituto de Previdência Social dos Servidores do Estado de Minas Gerais; 2007.

2 Centro Universitário de Belo Horizonte, Curso de Nutrição, Departamento de Ciências Biológicas, Ambientais e da Saúde. Av. Prof. Mário Werneck, 1685, Bl. B8, 4º andar, Buritis, 30455-610, Belo Horizonte, MG, Brasil. Correspondência para/Correspondence to: M.C.A.P. DIAS.E-mails: <maraclaudiadias@bol.com.br>; <mcazevedo@unibh.acad.br>.

3 Universidade Federal de Minas Gerais, Faculdade de Medicina, Departamento de Pediatria. Belo Horizonte, MG, Brasil.

${ }^{4}$ Universidade Federal de Viçosa, Curso de Nutrição, Departamento de Nutrição e Saúde. Viçosa, MG, Brasil.
} 
476 | M.C.A.P. DIAS et al.

\section{A B S T R A C T}

The objective of the present study was to review the current recommendations on the complementary feeding of children younger than two years of age. The keyword weaning was used to search the databases SciELO, MedLine and Lilacs for articles on the subject. Publications from the World Health Organization and the Brazilian Ministry of Health were also included. The inclusion criteria for the articles were children from 0 to 23 months of age, articles published from 2002 to 2006 and articles published in the languages Portuguese, English and Spanish. Much scientific evidence has accumulated over the last years regarding the importance of exclusive breastfeeding in the first six months, of appropriate complementary feeding and of breastfeeding until age two years or more. Appropriate complementary feeding should include foods that are rich in energy, protein and micronutrients, free from contaminations, without excess salt or spices, in adequate amounts and easy to prepare, ensuring correct consistency and energy density. The family has a decisive role in the formation of new habits, control of food intake and development of an eating behavior that may or may not be appropriate. The introduction of complementary foods is a critical stage and there are many disadvantages to the use of nonhuman milk and early and/or incorrect introduction of foods. It is the responsibility of health professionals to advise parents on the best complementary feeding practices and guide governmental actions aimed at the full growth and development of children under 2 years of age.

Indexing terms: Breastfeeding. Complementary feeding. Weaning, infant.

\section{N T R O D U ÇÃ O}

O primeiro ano de vida é um período caracterizado por rápido crescimento e desenvolvimento. Até dois anos, o crescimento reflete as condições da vida intrauterina e de fatores ambientais, dentre os quais se destaca o estado nutricional. Dessa forma, alterações de crescimento nesse período têm como causa mais provável o deficit nutricional pregresso ou atual ${ }^{1}$. O deficit de crescimento linear adquirido na infância é difícil de ser revertido após os dois anos; a alimentação dessa fase, portanto, tem repercussões ao longo de toda a vida do indivíduo².

A demanda nutricional do lactente é prontamente atendida pelo aleitamento materno exclusivo até os seis meses de vida. A partir daí torna-se necessária a introdução da alimentação complementar, visando o fornecimento de energia, proteínas, vitaminas e minerais ${ }^{3}$. A adequação nutricional dos alimentos complementares é fundamental na prevenção de morbimortalidade na infância, incluindo a desnutrição e o sobrepeso ${ }^{4,5}$. Nos últimos anos têm ocorrido avanços importantes na promoção da amamentação, no entanto a promoção da alimentação complementar tem menores progressos. Nesse contexto, atingir a alimentação adequada das crianças na primeira infância deve ser um componente essencial da estratégia global para a segurança alimentar de uma população.

Novos conhecimentos sobre a alimentação ideal de crianças menores de dois anos tornaram obsoletos conceitos e recomendações que fizeram parte da prática pediátrica por muitos anos. Este artigo faz uma revisão das evidências que embasam as recomendações atuais sobre a alimentação complementar na tentativa de contribuir para o incentivo ao aleitamento materno, para a promoção da alimentação saudável e do crescimento e do desenvolvimento adequados de crianças menores de dois anos.

\section{MÉ TODOS}

A revisão da literatura sobre o assunto foi realizada a partir da pesquisa em banco de dados SciELO, MedLine e Lilacs, livros técnicos e publicações de órgãos nacionais e internacionais. Para a pesquisa nos bancos de dados, utilizou-se o descritor "desmame" ou weaning, considerado um descritor universalmente aceito, e definiram-se os limites de crianças de 0 a 23 meses, período de publicação de 2002 a 2006 e idioma de redação em português, inglês e espanhol. Foram definidos o limite dos últimos cinco anos e a preferência por artigos nacionais devido à grande oferta de 
dados sobre o assunto, além das publicações da Organização Mundial da Saúde (OMS) e do Ministério da Saúde do Brasil.

\section{Alimentação}

Alimentação infantil ou da criança é definida como todo processo alimentar, comportamental e fisiológico que envolve a ingestão de alimentos pela criança. $\mathrm{O}$ termo aleitamento materno exclusivo é usado para definir o provimento de todos os líquidos, energia e nutrientes exclusivamente através do leite materno, diretamente da mama ou extraído, com a possibilidade do uso de algum suplemento medicamentoso. Aleitamento materno predominante é definido quando o lactente recebe, além do leite materno, água ou bebidas à base de água, como suco de frutas e chás. Aleitamento parcial é a denominação usada para o aleitamento materno com adição de outros alimentos ${ }^{6,7}$.

A alimentação complementar é compreendida como a alimentação fornecida no período em que outros alimentos ou líquidos são oferecidos em adição ao leite materno. Qualquer alimento ou líquido oferecido à criança, além do leite materno, nesse período é chamado de "alimento complementar", que é subdividido em duas categorias: alimentos transicionais - preparados exclusivamente para a criança e modificados para atender suas habilidades e necessidades - e alimentos complementares não modificados e consumidos pelos demais membros da família e que não recebem denominação específica, podendo ser classificados como alimentos familiares. 0 termo "alimentos de desmame", anteriormente utilizado como sinônimo de alimento complementar, não é recomendado, pois sua interpretação errônea pode dar a impressão de que os alimentos são introduzidos para substituir o leite materno, causando o desmame em vez de complementar a amamentação. O uso do termo "desmame" também é desaconselhável, pois pode ser entendido erroneamente como a parada total da amamentação, interferindo negativamente na promoção do aleitamento materno. Recomenda-se, atualmente, o termo "desmame total" para indicar a interrupção total da amamentação ${ }^{4,7}$.

\section{Duração ótima do aleitamento materno exclusivo}

Nos últimos anos acumularam-se evidências científicas sobre a importância da amamentação exclusiva nos primeiros seis meses, da alimentação complementar oportuna e da manutenção do aleitamento materno até os dois anos de idade ou mais². As dúvidas e controvérsias, surgidas no final dos anos 1970 , persistiram até o ano 2001, quando consultores internacionais da OMS realizaram uma revisão sistemática da literatura científica buscando suporte para definir a duração ótima do aleitamento materno exclusivo e, consequentemente, a idade segura e apropriada de introdução dos alimentos complementares $^{2,8}$. O resultado dessa revisão deu origem à proposta de Estratégia Global para a alimentação infantil, apresentada na 54a Assembléia Mundial da Saúde, realizada em maio de 2001 e aprovada na $55^{a}$ Assembléia Mundial da Saúde9. A partir daí, a OMS recomendou a promoção do aleitamento materno exclusivo até seis meses de idade, em substituição à recomendação anterior que era de 4 a 6 meses $^{3}$. Recomendou, ainda, a introdução de alimentos complementares nutricionalmente adequados, inócuos e culturalmente apropriados, a partir de seis meses, com manutenção da amamentação por dois anos ou mais ${ }^{3,10}$. Essas recomendações internacionais são resultado de diversos trabalhos científicos que propuseram revisão das práticas alimentares infantis, quando finalmente se estabeleceu um consenso mundial de que não há nenhum benefício que possa justificar a introdução precoce de alimentos complementares antes dos seis meses $3,4,8,10$.

Por muitos anos permaneceram desconhecidos o valor nutricional e imunológico do leite materno, o valor do ato de amamentar e suas consequências fisiológicas, emocionais e de menor morbidade para a criança e para a mãe. Sabe-se 
que todo o processo biológico de desenvolvimento do lactente pode ser influenciado pela prática alimentar nos primeiros meses de vida ${ }^{11}$. Os conhecimentos das últimas duas décadas evidenciaram que vários são os agravos decorrentes da não amamentação.

Victora et al. ${ }^{12}$ demonstraram que quanto maior a prática do aleitamento materno exclusivo, menor o risco de mortalidade por diarreia e outras infecções. Há evidências também de que o uso do leite materno para recém-nascidos prematuros e de baixo peso aumenta os índices de crescimento, de inteligência e de acuidade visual ${ }^{13}$. A partir dos seis meses as necessidades do lactente não podem mais ser supridas exclusivamente pelo leite materno, tornando-se necessária a introdução da alimentação complementar para adequar o fornecimento de energia, proteínas, vitaminas e minerais ${ }^{3}$. Também é a partir dessa idade que a maioria das crianças atinge seu desenvolvimento neurológico e motor-oral, o que possibilita a introdução de outros alimentos ${ }^{14}$.

\section{Introdução da alimentação complementar precoce}

Nos últimos anos vários estudos vêm demonstrando os agravos significativos quando a amamentação não acontece. Na fase inicial da vida, o leite humano é indiscutivelmente o alimento que reúne as características nutricionais ideais, com balanceamento adequado de nutrientes, além de favorecer inúmeras vantagens imunológicas e psicológicas importantes na diminuição da morbidade e mortalidade infantil. A amamentação é, então, fundamental para a criança, para a mãe, para a família e a sociedade em geral ${ }^{15}$. O principal argumento contra a introdução precoce dos alimentos complementares é o aumento dos riscos de morbi-mortalidade, especialmente em regiões com condições precárias de higiene. Oferecer à criança outros alimentos além do leite materno antes do sexto mês de vida pode tornar a criança mais vulnerável a diarreias, a infecções respiratórias e gastrintestinais e a desnutrição, levando ao comprometimento do crescimento e

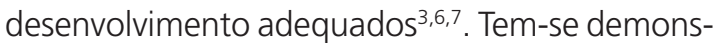
trado, ainda, que a introdução precoce de alimentos aumenta a morbimortalidade infantil como consequência de uma menor ingestão dos fatores de proteção do leite materno ${ }^{16,17}$.

A oferta inadequada de nutrientes é crítica nos primeiros anos de vida, quando a capacidade de utilizar efetivamente os nutrientes é limitada devido à imaturidade biológica, caracterizada por relativa imaturidade fisiológica: reflexo de protrusão da língua, pouca produção de amilase salivar e pancreática, limitada função renal e mucosa intestinal permeável a proteínas heterólogas $11,18,19$. O desmame precoce está associado à sobrecarga do sistema imune e à imaturidade dos rins e do intestino ${ }^{17}$.

Os dados da literatura são contraditórios quanto ao crescimento ou velocidade de crescimento de crianças em aleitamento materno, sobretudo pela diversidade dos métodos de investigação utilizados $^{20}$. Na busca de um consenso sobre a duração ótima do aleitamento materno exclusivo e a idade de introdução dos alimentos complementares, a OMS fez uma revisão sistemática de 2668 pesquisas publicadas nas principais bases de dados, sem restrição de línguas ${ }^{3}$. Não foram encontradas evidências para o chamado "dilema do desmame". Lactentes alimentados exclusivamente com leite materno até seis meses tiveram menor morbidade por infecção gastrintestinal quando comparados àqueles alimentados exclusivamente até três ou quatro meses. Não foi demonstrado deficit no crescimento das crianças de países desenvolvidos ou mesmo de países em desenvolvimento. E, ainda, as mães dessas crianças tiveram tempo prolongado de amenorreia lactacional ${ }^{3}$.

Em um estudo nacional, 102 crianças alimentadas exclusivamente ao seio nos seis primeiros meses de vida apresentaram ganho ponderal adequado quando comparado aos padrões existentes, sendo acentuado nos primeiros quatro meses e desacelerado posteriormente. Todas as 
crianças dobraram seu peso de nascimento antes do quarto mês de vida, chegando aos seis meses eutróficas, com médias de peso superiores às do National Center for Health and Statistics (NCHS) ${ }^{15}$. O crescimento estatural também se apresentou adequado, com desaceleração após os quatro meses de idade. Vale ressaltar que as atuais curvas de crescimento são baseadas em crianças alimentadas artificialmente e que, na ausência de curvas de crescimento para lactentes alimentados exclusivamente com leite materno, os resultados dos estudos disponíveis devem ser interpretados com cautela. Sugere-se, no entanto, que o crescimento de crianças amamentadas seja frequentemente inferior ao de crianças não amamentadas, sem que isso implique nenhum prejuízo funcional3,3,15.

Em resposta a essa discussão, a OMS coordenou um estudo multicêntrico em seis países (Brasil, Estados Unidos, Gana, Índia, Noroega e Oman) para a elaboração de novos padrões de referência de crescimento, construídos a partir de crianças alimentadas com leite materno exclusivo até, pelo menos, os quatro meses, e com complementação até, pelo menos, 12 meses. A construção de novas curvas de referência foi aprovada em 1994, durante a Assembléia Mundial de Saúde da OMS, e o estudo foi conduzido de 1997 a 2003, em países diferentes, de modo a representar as principais regiões geográficas do mundo. Em abril de 2006, foram publicadas as Curvas de Crescimento da Organização Mundial de Saúde, que revelam como cada criança no mundo deve crescer, desde que suas necessidades básicas sejam garantidas. É um instrumento para medir, monitorar e avaliar o crescimento de todas as crianças, independentemente da origem étnica, situação socioeconômica ou tipo de alimentação ${ }^{21}$.

As crianças amamentadas exclusivamente ao seio, mesmo nos países desenvolvidos, mostram uma diminuição do índice peso/idade a partir do terceiro mês, que se mantém até o final do primeiro ano de vida, quando comparadas com a população de referência ${ }^{22}$. O mesmo ocorre com o índice comprimento/idade, porém com uma diminuição menos acentuada e uma tendência a se estabilizar ou mesmo aumentar após o oitavo mês. Entretanto, esse crescimento mais lento não é revertido com a introdução de alimentos complementares adequados aos quatro meses ${ }^{6}$.

Outro aspecto a ser considerado é a técnica da amamentação. A criança que não abocanha adequadamente a mama (cerca de dois centímetros do tecido mamário, além do mamilo) pode apresentar deficit de ganho de peso, apesar de permanecer por tempo prolongado ao seio. Muitas vezes, o bebê com pega incorreta é capaz de obter o chamado leite anterior, mas tem dificuldade em obter o leite posterior, mais nutritivo e rico em gorduras, o que pode repercutir no seu ganho de peso. Nesses casos, a correção da pega, e não a introdução de alimentos complementares, garante à criança o crescimento adequado ${ }^{23}$. Portanto, se a criança amamentada não estiver crescendo adequadamente ao final do primeiro ano e no segundo ano de vida, os esforços devem concentrar-se na melhora da qualidade nutricional e da quantidade dos alimentos complementares e não na interrupção da amamentação $0^{6,7}$.

Mais recentemente, tem-se relacionado a introdução precoce dos alimentos complementares com o aparecimento de doenças alérgicas. A sensibilização precoce pode estar associada ao desenvolvimento de asma e eczema ou dermatites atópicas. O efeito protetor do leite materno parece persistir durante a primeira década de vida, sendo particularmente evidente em crianças com história familiar de doenças atópicas ${ }^{24-26}$.

O aleitamento materno também tem efeitos positivos no crescimento e desenvolvimento craniofacial e motor-oral do recém-nascido. A literatura ainda tem apontado para a importância da sucção durante o aleitamento materno, pois ela promove o desenvolvimento adequado dos órgãos fonoarticulares quanto à mobilidade e postura e das funções de respiração, mastigação, deglutição e articulação dos sons da fala. A introdução precoce dos alimentos complementares pode levar à ruptura do desenvolvimento motor-oral adequado $^{14}$. 
Novas evidências discutem a associação entre introdução precoce dos alimentos complementares e baixo peso ao nascer como fator de risco para aterosclerose. Essas evidências trazem novas preocupações à saúde pública, tanto em países desenvolvidos, que ainda mantêm elevados índices de desmame precoce, mas principalmente nos mais pobres, que, ao lado da baixa duração do aleitamento materno, também apresentam elevados índices de baixo peso ao nascer ${ }^{27}$.

Sob o ponto de vista nutricional, a introdução precoce pode ser desvantajosa, pois, além de reduzir a duração do aleitamento materno, pode interferir na absorção de nutrientes importantes do leite materno, como o ferro e o zinco, e está relacionada à maior ocorrência de doenças crônicas não transmissíveis na idade adulta ${ }^{4,28}$. A complementação com outros líquidos não nutritivos diminui o volume total do leite materno ingerido, independentemente do número de mamadas, e precipita a introdução da mamadeira ${ }^{7,14,29}$. Essa prática pode ser prejudicial uma vez que a mamadeira é uma importante fonte de contaminação, reduz o tempo de sucção das mamas, interferindo na amamentação sob livre demanda, retarda o estabelecimento da lactação, além de alterar a dinâmica oral. Vários estudos relatam a associação entre o uso da mamadeira e o desmame precoce $^{7,8,14}$.

\section{Fatores associados ao desmame precoce}

Considerando-se que a prática do aleitamento materno ainda mantém-se distante das recomendações dos organismos mundiais ${ }^{3,16}$, verifica-se a necessidade de identificação dos fatores associados ao desmame de forma a favorecer a operacionalização das ações de incentivo ao aleitamento materno e orientação adequada quanto à introdução dos alimentos complementares.

O aleitamento materno, além de ser um ato biológico, é social e psicologicamente delineado. A cultura, a crença e os tabus influenciam de forma crucial a sua prática, interferindo na construção de uma herança sociocultural e no significado do aleitamento materno para a mulher. Dessa maneira, a amamentação, as crenças transmitidas por familiares, o crescimento e o desenvolvimento da criança são alguns dos fatores relacionados à prevalência do aleitamento materno ${ }^{23}$. Verifica-se que as crianças das áreas rurais ainda são mais amamentadas do que as das áreas urbanas. A amamentação parece ser um processo mais difícil para as mães que residem na área urbana, por sofrerem elas as pressões do trabalho fora do $\operatorname{lar}^{29}$ e da modernização ${ }^{18,30,31}$. A introdução precoce dos alimentos complementares tem sido associada à opinião contrária das avó ${ }^{32}$, à prematuridade e ao baixo peso ao nascer ${ }^{8,33}$, à baixa escolaridade materna e à renda familiar ${ }^{16,34,35}$, à idade materna inferior a 20 anos 8,31,35, ao uso de chupetas e de mamadeiras 8,31 .

A utilização de chupetas e mamadeiras, especialmente no início da amamentação, pode retardar o estabelecimento da lactação por confundir o reflexo de sucção do recém-nascido, desfavorecendo, consequentemente, o estímulo de produção de leite. Estudos demonstram ainda que a complementação do leite materno com líquidos não nutritivos, como chás e água, nos primeiros meses de vida é prática inadequada e desnecessária sob o aspecto biológico, mesmo considerando dias quentes e secos. Credita-se a essas infusões propriedades calmantes e laxativas. Deve-se considerar que, em crianças amamentadas, essa complementação está associada à redução do consumo total de leite materno, podendo culminar com o desmame precoce $8,31,36$.

\section{Alimentação complementar adequada}

Uma alimentação infantil adequada compreende a prática do aleitamento materno e a introdução, em tempo oportuno, de alimentos apropriados para complementar o aleitamento materno ${ }^{6}$.

A alimentação complementar adequada deve compreender alimentos ricos em energia e 
micronutrientes (particularmente ferro, zinco, cálcio, vitamina $A$, vitamina $C$ e folato), sem contaminação (isentos de microorganismos patogênicos, toxinas ou produtos químicos prejudiciais), sem excesso de sal ou condimentos, evitando-se alimentos industrializados, em quantidade apropriada, a partir de alimentos de fácil preparação, utilizados pela família e de custo aceitável ${ }^{7,36}$. O planejamento da refeição de sal deve contemplar alimentos dos grupos de cereal ou tubérculo, alimento proteico de origem animal, leguminosas e hortaliças ${ }^{36}$.

A introdução de novos alimentos deve ser gradual, um de cada vez, com intervalos de três a sete dias, a fim de identificar possíveis reações alérgicas ao alimento ${ }^{4,37}$. Glúten, ovos, peixes e castanhas devem ser evitados para crianças menores de um ano, em famílias com história de alergias alimentares ${ }^{10,38}$. Em geral, as crianças tendem a rejeitar alimentos desconhecidos, fenômeno denominado neofobia alimentar, que não deve ser interpretado erroneamente como aversão permanente ao alimento. Esse comportamento pode manifestar-se tão cedo quanto em crianças de seis meses. Em média são necessárias de oito a dez exposições para que o alimento seja aceito e incorporado à dieta da criança ${ }^{6,39}$. A preferência por determinado tipo de alimento decorre de um processo de aprendizagem. Dessa forma, as crianças aprendem a ter maior preferência pelos alimentos que são oferecidos com maior frequência. Para facilitar a aceitação de uma alimentação variada, a criança deve ser exposta, em tempo oportuno, aos diferentes tipos de alimentos ainda no primeiro ano de vida ${ }^{6,36}$.

\section{Alimentação responsável}

O comportamento alimentar da criança é determinado pela interação da criança com o alimento, pelo seu desenvolvimento anatomofisiológico e por fatores emocionais, psicológicos, socioeconômicos e culturais. Deve-se considerar, entretanto, que a influência mais marcante na formação dos hábitos alimentares é o produto da interação da criança com os pais ou com a pessoa responsável pela sua alimentação, que desenvolvem o papel dos primeiros educadores nutricionais $^{28}$.

Os fatores culturais e psicossociais influenciam as experiências alimentares da criança desde o momento do nascimento, por meio do processo de aprendizagem. O contexto social exerce papel preponderante, sobretudo nas estratégias que os pais utilizam para alimentar a criança ou para estimulá-la a comer alimentos específicos ${ }^{39}$. O ambiente doméstico, o estilo de vida dos pais, as relações interfamiliares podem ter grande influência na alimentação, nas preferências alimentares, e afetar o equilíbrio nutricional da alimentação pela disponibilidade e composição dos alimentos. Assim, a família tem papel decisivo no aprendizado de hábitos socialmente aceitos, na formação de novos hábitos, no autocontrole da ingestão alimentar e na formação de um padrão de comportamento alimentar adequado ou não 28,37,40.

A OMS recomenda às mães/cuidadores a prática de alimentação responsável, que usa os princípios de cuidados psicossociais. A prática inclui o respeito ao mecanismo fisiológico de autorregulação do apetite da criança. Recomenda-se alimentar a criança, lenta e pacientemente, até que se sacie, jamais forçando-a a comer. Em casos de recusa, pode-se experimentar diferentes combinações, sabores, texturas e métodos de encorajamento não coercivos, desde que não distraiam a criança da refeição, que deve ser um momento de aprendizado que inclui atenção, conversa e contato visual entre a mãe/cuidador e a criança ${ }^{10,41}$.

\section{Consistência}

A criança pode ser alimentada com os alimentos disponíveis para a família, assegurando-se a consistência e a densidade energética adequadas $^{36}$. Atualmente, tem-se dado atenção à viscosidade dos alimentos complementares, que está relacionada com sua densidade energética. $A$ pequena capacidade gástrica impede que as 
crianças pequenas supram suas necessidades energéticas por meio de alimentos diluídos. As sopas e os mingaus muito diluídos e oferecidos em mamadeiras devem ser desencorajados ${ }^{4,6,34}$.

A OMS recomenda que a alimentação complementar deva iniciar aos seis meses com pequenas quantidades de alimentos e aumente, gradativamente, à medida que a criança cresce. A consistência deve ser adaptada às suas necessidades e habilidades. O desenvolvimento neurológico da criança determina a idade de introdução dos diferentes tipos de alimentos. Lactentes aos seis meses devem consumir alimentos semissólidos e macios (sob a forma de purês), podendo ser amassados, porém nunca liquidificados ou coados. A partir dos oito meses, a criança pode receber alimentos amassados, desfiados, picados ou cortados em pedaços pequenos. Aos dez meses devem ser oferecidos alimentos granulosos. Aos doze meses, a maioria das crianças pode receber os mesmos alimentos da família, evitando-se alimentos que possam oferecer riscos de engasgos, como nozes, uvas, sementes, cenouras cruas e outros. A consistência inadequada dos alimentos compromete sua ingestão. Já as crianças que não recebem alimentos semissólidos por volta de dez meses podem apresentar maior dificuldade de aceitação alimentar posteriormente 4,10,41,42. Recomenda-se ainda que os alimentos sejam oferecidos separadamente para que a criança possa reconhecer cores, texturas e sabores diferentes ${ }^{36}$.

\section{Densidade energética}

As recomendações energéticas para as crianças menores de dois anos de idade têm sido sucessivamente revistas por grupos de especialistas ao longo dos anos. Vários parâmetros têm sido usados nas estimativas devido às dificuldades metodológicas para determinação de necessidades de energia nessa faixa etária. As recomendações da OMS ${ }^{7}$ para a ingestão de energia, para crianças nos primeiros dois anos de vida, baseiam-se na ingestão de energia de crianças sadias, vivendo em sociedades desenvolvidas, adicionadas de 5\%, para corrigir uma eventual subestimativa da inges- tão do leite materno. As atuais necessidades de energia segundo a Estimated Energy Requirement (EER) foram estimadas em 512kcal/dia para crianças de zero a três meses, $573 \mathrm{kcal} /$ dia para crianças de quatro a seis meses, e $676 \mathrm{kcal} /$ dia e $780 \mathrm{kcal} / \mathrm{dia}$ para crianças de sete a nove meses e dez a doze meses respectivamente ${ }^{43}$.

As estimativas de energia a ser fornecida pelos alimentos complementares estão em torno de 25 a $32 \%$ menores que as anteriores, segundo as novas recomendações da $\mathrm{OMS}^{10}$. As quantidades de energia que os alimentos complementares devem fornecer, para crianças menores de dois anos em países em desenvolvidos, em aleitamento materno, foram definidas em 200kcal/dia dos seis a oito meses, 300kcal/dia de nove a onze meses e 550kcal dos 12 aos 23 meses. Essas recomendações diferem das dos países industrializados devido às diferenças na ingestão média do leite materno, sendo definidas em 130, 310 e 580kcal/ dia, respectivamente ${ }^{10}$.

A criança autorregula a ingestão diária de energia, diminuindo a quantidade ingerida de alimentos de alta densidade calórica. Assim, crianças muito pequenas são capazes de ajustar o volume de alimentos ingeridos em resposta à sua densidade energética, consumindo volumes maiores de alimentos menos concentrados ${ }^{4,6}$. A pequena capacidade gástrica da criança pode impedir que as necessidades energéticas sejam alcançadas caso a dieta seja de baixa densidade energética. Por outro lado, quando a criança recebe grande quantidade de energia dos alimentos complementares, pode-se reduzir a ingestão do leite materno, o que é desaconselhável em crianças menores de um ano ${ }^{4}$. O Estudo Multicêntrico sobre Consumo Alimentar realizado no Brasil demonstrou que, em geral, a dieta das crianças brasileiras menores de dois anos é adequada em energia, embora a densidade energética das refeições seja baixa ${ }^{44}$.

\section{Proteínas}

Em geral, a quantidade de proteínas das dietas é adequada se houver um adequado con- 
sumo energético, exceto em populações de baixa renda que consomem predominantemente alimentos pobres em proteínas, como batata, farinha e mandioca ${ }^{3}$. A densidade proteica (gramas de proteínas por $100 \mathrm{kcal}$ de alimento) dos alimentos complementares recomendada é de $0,7 \mathrm{~g} / 100 \mathrm{kcal}$ dos seis aos vinte e quatro meses. Além da quantidade das proteínas da dieta, são importantes sua qualidade e digestibilidade. As proteínas de alto valor biológico e de melhor digestibilidade são encontradas em primeiro lugar no leite humano e depois nos produtos de origem animal (carnes em geral, leites e derivados e ovos). A dieta à base de vegetais também pode fornecer proteínas de boa qualidade, desde que contenha quantidade suficiente e combinação apropriada de vegetais. A soja e a mistura de arroz com feijão, por exemplo, fornecem proteínas de bom valor nutricional ${ }^{6}$.

\section{Ferro}

A carência de ferro, resultando em anemia ferropriva na infância, constitui o maior problema nutricional da atualidade. Afeta populações tanto de países desenvolvidos como de países em desenvolvimento. A deficiência de ferro tem sido associada a alterações de pele e mucosas, baixo peso para a idade, deficit motor, psicológico, comportamental, imunológico, cognitivo e de linguagem ${ }^{45,46}$.

No Brasil, não existe, até o momento, estudo com representatividade nacional que avalie a magnitude do problema da carência nutricional de ferro no país ${ }^{12}$. No entanto, estudos realizados em diferentes locais e em populações restritas indicam uma alta prevalência de anemia por deficiência de ferro, na ordem de $50 \%$ em crianças menores de dois anos, com grande homogeneidade em todo o país ${ }^{45,47}$. No município de São Paulo, um amplo estudo epidemiológico mostrou que mais da metade das crianças entre 6 e 24 meses estava anêmica ${ }^{48}$. No Sul do País, foi encontrada uma prevalência de $54 \%$ de anemia em crianças menores de três anos, sendo menos prevalente com o aumento da escolaridade paterna e a renda familiar total, evidenciando a força de desigualdade social na anemia ${ }^{46}$.

O leite materno, quando oferecido exclusivamente até os seis meses, apesar do baixo conteúdo de ferro, é capaz de suprir as necessidades do lactente nascido a termo, com peso adequado e de mães não anêmicas, devido às reservas hepáticas acumuladas durante a gestação. Além disso, deve-se considerar a alta biodisponibilidade do ferro no leite materno, atingindo um rendimento de utilização de até $70 \%$ do ingerido. A partir dos seis meses, as necessidades de ferro precisam ser supridas com os alimentos complementares ${ }^{6}$. A densidade de ferro recomendada nos alimentos complementares é de $4 \mathrm{mg} / 100 \mathrm{kcal}$ dos seis aos oito meses, de 2,4mg/100kcal dos 9 aos 11 meses e de $0,8 \mathrm{mg} / 100 \mathrm{kcal}$ dos 12 aos 24 meses $^{7}$.

Os conhecimentos atuais indicam que a quantidade adequada de ferro na alimentação complementar só pode ser atingida com uma alimentação variada, rica em produtos de origem animal - incluindo a carne -, e em alimentos que melhorem a biodisponibilidade do ferro (ácido ascórbico), no caso de alimentos de origem vegetal; restringindo os alimentos que exerçam efeito inibitório (cálcio, fitatos e oxalatos), além do uso de alimentos fortificados ${ }^{6,42}$. Vale ressaltar que a disponibilidade de alimentos fortificados com ferro é maior em países desenvolvidos do que em países em desenvolvimento, além do fato de esses alimentos e os de origem animal, com alta biodisponibilidade de ferro, serem de menor acesso para as famílias de baixa renda. O baixo acesso aos alimentos fontes de ferro, associado ao desmame precoce e às micro-hemorragias intestinais relacionadas ao uso de leite de vaca, são algumas das razões para a alta prevalência de anemia em crianças menores de dois anos no Brasil ${ }^{4,11,45,48}$.

Considerando a alta prevalência de anemia no mundo, a OMS recomenda a suplementação medicamentosa com sulfato ferroso para crianças de 6 a 23 meses que não tenham acesso a alimentos fortificados, ou em populações nas quais a prevalência de anemia é superior a 40\%. A dose profilática é de $2 \mathrm{mg} / \mathrm{kg}$ de peso corporal/ 
dia. Crianças nascidas com baixo peso ( $<2500 \mathrm{~g})$ ou pré-termo (<37 semanas) devem iniciar a suplementação aos dois meses de idade ${ }^{49}$. No Brasil, o Programa Nacional de Suplementação de Ferro do Ministério da Saúde, que tem por objetivo o controle e a redução da anemia ferropriva no país, distribui sulfato ferroso para a administração em doses semanais de $25 \mathrm{mg}$ de ferro elementar. A recomendação é a suplementação universal de crianças de 6 a 18 meses; no caso de crianças não amamentadas, a suplementação deve iniciar aos quatro meses. A prevenção global da anemia no país também inclui a fortificação obrigatória das farinhas de trigo e milho com ferro e ácido fólico ${ }^{50}$.

A Sociedade Brasileira de Pediatria ${ }^{36}$ recomenda a profilaxia com sulfato ferroso para crianças nascidas a termo, de peso adequado para idade gestacional, com $1 \mathrm{mg}$ de ferro elementar $/ \mathrm{kg}$ de peso corporal/dia, a partir da idade de introdução dos alimentos complementares até 24 meses ou $25 \mathrm{mg}$ em dose semanal até 18 meses. Não está indicada a suplementação de ferro para as crianças em aleitamento materno exclusivo e que recebam fórmulas infantis até o sexto mês, ou, ainda, se a partir desse período houver ingestão mínima de $500 \mathrm{ml} / \mathrm{dia}$. Para recém-nascido de baixo peso ou prematuro, a recomendação é de $2 \mathrm{mg} / \mathrm{kg}$ de peso corporal/dia durante todo primeiro ano de vida. Após esse período, segue-se a recomendação anterior.

\section{Promoção da alimentação complementar saudável}

No Brasil, o Ministério da Saúde, com apoio da Organização Pan-Americana da Saúde (OPAS), elaborou as recomendações alimentares para crianças menores de dois anos, denominada "Os dez passos para uma alimentação saudável das crianças menores de dois anos" (Quadro 1). Esse guia, elaborado após amplo levantamento de dados, objetiva promover práticas alimentares saudáveis para a criança pequena ${ }^{6}$.

\section{CONSIDERAÇÕ ES FINAIS}

Os prejuízos do aleitamento artificial e da introdução precoce e/ou inadequada dos alimentos complementares devem ser mais amplamente discutidos e divulgados e os pais e/ou responsáveis precisam ser aconselhados quanto aos princípios fisiológicos e nutricionais que norteiam a alimen-

Quadro 1. Os 10 passos para alimentação saudável das crianças menores de dois anos.

Passo 1 Dar somente leite materno até os 6 meses, sem oferecer água, chás ou qualquer outro alimento.

Passo 2 A partir dos seis meses, introduzir de forma lenta e gradual outros alimentos, mantendo o leite materno até os dois anos de idade ou mais.

Passo 3 Após seis meses, dar alimentos complementares (cereais, tubérculos, carnes, leguminosas, frutas, legumes) três vezes ao dia se a criança receber leite materno, e cinco vezes ao dia se estiver desmamada.

Passo 4 A alimentação complementar deve ser oferecida sem rigidez de horários, respeitando-se sempre a vontade da criança.

Passo 5 A alimentação complementar deve ser espessa desde o início e oferecida de colher; deve-se começar com consistência pastosa (papas/purês) e, gradativamente, aumentar a consistência até se chegar à alimentação da família.

Passo 6 Oferecer à criança diferentes alimentos ao longo do dia. Uma alimentação variada é uma alimentação colorida.

Passo 7 Estimular o consumo diário de frutas, verduras e legumes nas refeições.

Passo 8 Evitar açúcar, café, enlatados, frituras, refrigerantes, balas, salgadinhos e guloseimas nos primeiros anos de vida. Usar sal com moderação.

Passo 9 Cuidar da higiene no preparo e manuseio dos alimentos; e garantir armazenamento e conservação adequados.

Passo 10 Estimular a criança doente e convalescente a se alimentar, oferecendo a alimentação habitual e seus alimentos preferidos e respeitando sua aceitação.

Fonte: Brasil. Ministério da Saúde ${ }^{6}$. 
tação da criança. Aos profissionais da saúde, cabe incentivar o aleitamento materno e as práticas da alimentação complementar apropriadas, que compreendem a introdução, em tempo oportuno, de alimentos adequados para complementar o aleitamento materno. A alimentação complementar deve oferecer alimentos ricos em energia e micronutrientes, sem contaminação, sem muito sal ou condimentos, em quantidade apropriada e fácil de preparar a partir dos alimentos da família.

\section{COLABORADORES}

M.C.A.P. DIAS, L.M.S. FREIRE e S.C.C. FRANCESCHINI participaram na elaboração de estratégia experimental, na coleta de dados, na tabulação e na discussão dos resultados da dissertação que deu origem a este artigo e elaboração e redação do artigo de revisão.

\section{REFERÊ N CIAS}

1. Araújo MGM. Avaliação clínico-neurológico de recém-nascidos subnutridos e normais a termo: acompanhamento do desenvolvimento no primeiro ano de vida e detecção de alterações [tese]. Campinas: Unicamp; 1998,

2. Giugliani ERJ, Victora CG. Alimentação complementar. J Pediatr. 2000; 76 (Supl.3):S253-62.

3. World Health Organization. The optimal duration of exclusive breastfeeding: a systematic review. Geneva: OMS; 2002.

4. Monte CMG, Giugliani ERJ. Recomendações para alimentação complementar da criança em aleitamento materno. J Pediatr. 2004; 80(Supl 5):S131-41.

5. Ichisato SMT, Shimo AKK. Revisitando o desmame precoce através de recordes da história. Rev LatinoAm Enfermagem. 2002; 10(4):578-85.

6. Brasil. Ministério da Saúde. Guia alimentar para crianças menores de 2 anos. Brasília; 2002. Série A - Normas e Manuais Técnicos, n.107.

7. World Health Organization. Complementary feeding of young children in developing countries. Geneva: WHO; 1998.

8. Audi CAF, Correa MAS, Latorre MRDO. Alimentos complementares e fatores associados ao aleitamento materno e ao aleitamento materno exclusivo em lactentes até 12 meses de vida em Itabira, São Paulo, 1999. Rev Bras Saúde Matern Infantil. 2003; 3(1):85-93.
9. World Health Organization. Infant and young child nutrition. In: Organização Mundial de Saúde 55a Assembléia Mundial da Saúde: 2002 May 18. Geneva: WHO; 2002.

10. World Health Organization. Guinding principles for complementary feeding of the breastfed child. Geneva: WHO; 2001.

11. Vitolo MR. Nutrição: da gestação à adolescência. Rio de Janeiro: Reichmann \& Affonso; 2003.

12. Victora CG, Smith PG, Vanghan JP, Nobre LC, Lombardi C, Teixeira AM, et al. Evidence for protection by breastfeeding against infant deaths from infectious deseases in Brazil. Lancet. 1987; 2(8554):319-22.

13. Rea MF. Reflexões sobre a amamentação no Brasil: de como passamos a 10 meses de duração. Cad Saúde Pública. 2003; 19(Supl.1):S37-45.

14. Neiva FCB, Cattoni DM, Ramos JLA, Issler H. Desmame precoce: implicações para o desenvolvimento motor-oral. J Pediatr. 2003; 79(1):7-12.

15. Marques RFSV, Lopez FA, Braga JAP. O crescimento de crianças alimentadas com leite materno exclusivo nos primeiros 6 meses de vida. J Pediatr. 2004; 80(2):99-105.

16. Simon VGN, Souza JMP, Souza SB. Introdução de alimentos complementares e sua relação com variáveis demográficas e socioeconômicas, em crianças no primeiro ano de vida, nascidas em Hospital Universitário no município de São Paulo. Rev Bras Epidemiol. 2003; 6(1):29-38.

17. Wright CM, Parkinson KN, Drewett RF. Why babies weaned early? Data from a prospective population based cohort study. Arch Dis Child. 2004; 89: 813-6.

18. Behar M. Physiological development of the feeding. Indian Pediatr. 1987; 24:837-58.

19. Lebenthal E, Leung YK. The impact of development of the gut on infant nutrition. Pediatric Ann. 1987; 16:211-20.

20. Morgan JB, Lucas A, Fewtrell MS. Does weaning influence growth and health up to 18 months? Arch Dis Child. 2004; 89:728-33.

21. World Health Organization. Child growth standards: methods and development. Geneva: OMS; 2006.

22. Centers for Disease and Prevention. Nacional Center for Health and Statistics. 2000 CDC Growth charts: United States [Internet]. Hyaltsville; 2002. Available from: <http://www.cdc.gov.growthcharts>.

23. Ichisato SMT, Shimo AKK. Aleitamento materno a crenças alimentares. Rev Latino-Am Enfermagem. 2001; 9(5):70-6.

24. Lack G, Khakoo GA. Introdution of solid to the infant diet. Arch Dis Child. 2004; 89:295. 
25. van Odjik J, Kull I, Boves MP, Brandtzaeg P, Edberg $V$, Hanson LA, et al. Breastfeeding and allergic disease: a multidisciplinary review of the literature (1966-2001) on the mode of early feeding and its impact on later atopic manifestations. Allergy 2003; 58(9):833-43. doi: 10.1034/j.1398-9995.20 03.00264.x.

26. Zutavern A, von Mutius E, Harris J, Mills P, Moffatt $S$, White $C$, et al. The introduction of solids in relation to asthma and eczema. Arch Dis Child. 2004; 89:303-8. doi: 10.1136/adc.2002.025353.

27. Alves JGB. Baixo peso ao nascer e desmame precoce: novos fatores de risco para aterosclerose. J Pediatr. 2004; 80(4):338.

28. Vieira GO, Silva LR, Vieira TO, Almeida JAG, Cabral VA. Hábitos alimentares de crianças menores de 1 ano amamentadas e não-amamentadas. J Pediatr. 2004; 80(5):411-6.

29. Saldiva SRDM Escuder MM, Mondini L, Levv RB, Venâncio SI. Práticas alimentares de crianças de 6 a 12 meses e fatores maternos associados. J Pediatr. 2007; 83(1):53-8.

30. Instituto Brasileiro de Geografia e Estatística. Bem-estar familiar no Brasil. Pesquisa nacional sobre demografia e saúde. Rio de Janeiro: IBGE; 1996.

31. Lima TM, Osório MM. Perfil e fatores associados ao aleitamento materno em crianças menores de 25 meses da região Nordeste do Brasil. Rev Bras Saúde Mater Infant. 2003; 3(3):305-14.

32. Alder EM, Willians FLR, Anderson AS, ForsytlH S, Florey $C V$, van der Velde $P$. What influences the timing of the introduction of solid food to infants? Br J Nutr. 2004; 92(3):527-37. doi: 10.1079/BJN20 041212.

33. Fewtrell MS, Lucas A, Morgan JB. Factors associated with weaning in full term and preterm infants. Arch Dis Child Fetal Neonatal. 2003; 88:F296-F301.

34. Brunken GS, Silva SM, França GVA, Escuder MM, Venâncio SI. Fatores associados à interrupção precoce do aleitamento materno exclusivo e à introdução tardia da alimentação complementar no centro-oeste brasileiro. J Pediatr. 2006; 82(6): 445-51.

35. Bueno MB, Souza JMP, Souza SB, Paz SMRS, Gimono SGA, Siqueira AAF. Riscos associados ao processo de desmame entre crianças nascidas em hospital universitário de São Paulo, entre 1998 a 1999: estudo de coorte prospectivo do primeiro ano de vida. Cad Saúde Pública. 2003; 19(5):1453-60. doi: 10.1590/S0102-311×2003000500024

36. Sociedade Brasileira de Pediatria. Manual de orientação para alimentação do lactente, do pré-escolar, do escolar, do adolescente e na escola. São Paulo: SBP; 2006.

37. Danowski L, Gargiula L. Selections from current literature: attitudes and practices regarding the introduction of solid foods to infant. Fam Pract. 2002; 19:698-702.

38. Van Odjik J, Hulthén L, Ahlsedt S, Borres MP. Introdution of food during the first year: a study with emphasis on introtution of gluten and of egg, fish and peanut in allergy-risk families. Acta Paediatric. 2004; 93(4):464-70.

39. Ramos M, Stein LM. Desenvolvimento do comportamento alimentar infantil. J Pediatr. 2000; 76(Supl 3): S229-37.

40. Salve JM, Silva IA. Representações sociais de mães sobre a introdução de alimentos complementares para lactentes. Acta Paul Enferm. 2009; 22(1): 43-8.

41. World Health Organization. Complementary feeding. Report of the global consultation: summary of guinding principles. Geneva: WHO; 2002.

42. Foot KD, Marriott LD. Weaning of infants. Arch Dis Child. 2003; 88:488-92.

43. Institute of Medicine. Dietary reference intakes for energy, carbohydrate, fiber, fat, fatty acids, cholesterol, protein and aminoacids. Washington (DC): National Academy Press; 2002.

44. Galeazzi MA, Domene SSA, Schicri SP. Estudo multicêntrico sobre consumo alimentar. Cad Debate. 1997; Volume Especial.

45. Hadler MCCM, Juliano Y, Sigulem DM. Anemia da lactente: etiologia e prevalência. J Pediatr. 2002; 78(4):321-6

46. Neuman NA, Tanaka OU, Szarfarc SC, Guimarães PR, Victora CG. Prevalência e fatores de risco para anemia no Sul do Brasil. Rev Saúde Pública. 2000; 34(1):56-63.

47. Silva DG, Frandochini SCC, Priori SE, Ribeiro SMR, Svarfara SC, Souza SB, et al. Anemia ferropriva em crianças de 6 a 12 meses atendidas na rede pública de saúde do município de Viçosa, Minas Gerais. Rev Nutr. 2002; 13(3):301-8. doi: 10.1590/S1415-S2 732002000300006 .

48. Monteiro CA, Szarfarc SC. Estudo das condições de saúde no Município de São Paulo, SP (Brasil), 1984-1985: V anemia. Rev Saúde Pública. 1987; 21(3):255-60.

49. World Health Organization. Iron deficiency anaemia: assesssment, prevention and control - a guide for programme mananger. Geneva: WHO; 2001.

50. Brasil. Ministério da Saúde. Manual operacional do Programa nacional de suplementação de ferro. Brasília: MS; 2005.

Recebido em: 11/12/2007

Versão final reapresentada em: 14/7/2009 Aprovado em: 11/11/2009 